Int. J. Electrochem. Sci., 13 (2018) $9214-9230$

International Journal of

ELECTROCHEMICAL

SCIENCE

www.electrochemsci.org

\title{
Degradation of 4-Chlorophenol in Aqueous Solution by Sono- Electro-Fenton Process
}

\author{
Roya Nazari ${ }^{1}$, Ljiljana Rajićl ${ }^{1}$ Yunfei Xue ${ }^{1,3}$, Wei Zhou ${ }^{1,2}$, Akram N. Alshawabkeh ${ }^{1, *}$ \\ ${ }^{1}$ Department of Civil and Environmental Engineering, Northeastern University, 400 Snell \\ Engineering, 360 Huntington Avenue, Boston, MA 02115, USA. \\ ${ }^{2}$ Department of Energy Science and Engineering, Harbin Institute of Technology, Harbin 150001, P.R. \\ China \\ ${ }^{3}$ State Environmental Protection Key Laboratory of Environmental Risk Assessment and Control on \\ Chemical Process, East China University of Science and Technology, Shanghai 200237, P.R. China \\ *E-mail: aalsha@coe.neu.edu
}

doi: $10.20964 / 2018.09 .46$

Received: 10 May 2018 / Accepted: 8 June 2018 / Published: 5 August 2018

Electro-Fenton (EF) and ultrasound radiation (US) have been of interest for the removal of chlorinated compounds from water. This study evaluates the effects of different parameters on sono-electro-Fenton (SEF) for degradation of 4-chlorophenol (4-CP) in an aqueous solution. This study uses pulsing US waves along with Pd-catalyzed EF to degrade contaminants in water while maintaining temperature. The usage of pulsing US waves along with Pd catalyzed EF to remove contaminants while maintaining temperature has not been reported previously. SEF ability to degrade 4-CP was compared with the performance of each process ( $\mathrm{EF}$ and sonolysis) alone. Initial $\mathrm{pH}$, current density, background electrolyte, $\mathrm{Fe}^{2+}$ concentration, $\mathrm{Pd} / \mathrm{Al}_{2} \mathrm{O}_{3}$ catalyst concentration, US waves, and sonifier amplitude were optimized in a two electrode (Ti/mixed metal oxide or Ti/MMO) batch system. The degradation of $4-\mathrm{CP}$ increased from $1.85 \%$ by US to $83 \%$ by EF to nearly $>99.9 \%$ by coupled SEF. With US radiation under $70 \%$ amplitude and 1:10 ON/OFF ratio, the removal rate of 4-CP increased to $98 \%$ compared to $62 \%$ under EF alone within the first $120 \mathrm{~min}$ in the presence of $80 \mathrm{mg} \mathrm{L}^{-1} \mathrm{Fe}^{2+}, 16.94 \mathrm{~mA}$ $\mathrm{cm}^{-2}$ of current density, $1 \mathrm{~g} \mathrm{~L}^{-1} \mathrm{Pd} / \mathrm{Al}_{2} \mathrm{O}_{3}$ catalyst $(10 \mathrm{mg} \mathrm{Pd})$, and initial $\mathrm{pH}$ of 3 . However, the degradation rate decreased after 120 min of treatment, and complete 4-CP removal was observed after 300 minutes. The sonolysis impacted the 4-CP removal under coupled SEF, mostly due to the contribution of mass transfer (micromixing), while radical formation was found to be absent under the conditions tested $(20 \mathrm{kHz})$. The pulsed US was found to increase the temperature by only $8.7^{\circ} \mathrm{C}$, which was found not to impact the 4-CP volatilization or degradation. These results imply that low-level US frequency through pulses is a practical and efficient approach to support electro-Fenton reaction, improving reaction rates without the need for electrolyte cooling. 
Keywords: Electro-Fenton process, Sono-Electro-Fenton process, 4-chlorophenol, Advanced oxidation processes, Pd catalysts.

\section{FULL TEXT}

(C) 2018 The Authors. Published by ESG (www.electrochemsci.org). This article is an open access article distributed under the terms and conditions of the Creative Commons Attribution license (http://creativecommons.org/licenses/by/4.0/). 